\title{
Ultrahypofractionation of localized prostate cancer
}

\author{
Statement from the DEGRO working group prostate cancer
}

\begin{abstract}
Frank Wolf ${ }^{1}$ (D) - Felix Sedlmayer ${ }^{1}$ - Daniel Aebersold ${ }^{2}$. Clemens Albrecht ${ }^{3}$ - Dirk Böhmer B Michael Flentje $^{5}$. Ute Ganswindt ${ }^{6}$. Pirus Ghadjar ${ }^{4}$ - Stefan Höcht ${ }^{7}$ - Tobias Hölscher ${ }^{8}$. Arndt-Christian Müller ${ }^{9}$. Peter Niehoff ${ }^{10}$. Michael Pinkawa ${ }^{11}$ • Nina-Sophie Schmidt-Hegemann ${ }^{12}$ • Constantinos Zamboglou'13 • Daniel Zips ${ }^{9}$. Thomas Wiegel ${ }^{14}$
\end{abstract}

Received: 12 November 2020 / Accepted: 17 November 2020 / Published online: 10 December 2020

(c) The Author(s) 2020

\begin{abstract}
Due to its low fractionation sensitivity, also known as "alpha/beta ratio," in relation to its surrounding organs at risk, prostate cancer is predestined for hypofractionated radiation schedules assuming an increased therapeutic ratio compared to normofractionated regimens. While moderate hypofractionation $(2.2-4 \mathrm{~Gy})$ has been proven to be non-inferior to normal fractionation in several large randomized trials for localized prostate cancer, level I evidence for ultrahypofractionation (>4 Gy) was lacking until recently. An accumulating body of non-randomized evidence has recently been strengthened by the publication of two randomized studies comparing ultrahypofractionation with a normofractionated schedule, i.e., the Scandinavian HYPO-RT trial by Widmark et al. and the first toxicity results of the PACE-B trial. In this review, we aim to give a brief overview of the current evidence of ultrahypofractionation, make an overall assessment of the level of evidence, and provide recommendations and requirements that should be followed before introducing ultrahypofractionation into routine clinical use.
\end{abstract}

Keywords Extreme hypofractionation $\cdot$ Radiotherapy $\cdot$ Hypofractionation $\cdot$ SBRT $\cdot$ SABR

$\triangle$ Frank Wolf

f.wolf@salk.at

1 Universitätsklinik für Radiotherapie und Radio-Onkologie, LKH, Universitätsklinikum, Paracelsus Medizinische Privatuniversität, Müllner Hauptstr. 48, 5020 Salzburg, Austria

2 Universitätsklinik für Radio-Onkologie, Inselspital, Universität Bern, Bern, Switzerland

3 Klinik für Radioonkologie und Gemeinschaftspraxis für Strahlentherapie, Klinikum Nürnberg Nord, Universitätsklinikum, Paracelsus Medizinische Privatuniversität, Nuremberg, Germany

4 Klinik für Radioonkologie und Strahlentherapie, Charité Universitätsmedizin, Berlin, Germany

5 Klinik und Poliklinik für Strahlentherapie, Universitätsklinikum Würzburg, Würzburg, Germany

6 Universitätsklinik für Strahlentherapie-Radioonkologie, Innsbruck, Austria

7 Xcare Praxis für Strahlentherapie Saarlouis, Xcare Gruppe, Saarlouis, Germany

$8 \quad$ Klinik und Poliklinik für Strahlentherapie und Radioonkologie, Universitätsklinikum Carl Gustav Carus, Technische Universität Dresden, Dresden, Germany

9 Universitätsklinik für Radioonkologie, Universitätsklinikum Tübingen, Tübingen, Germany

10 Sana Klinikum Offenbach, Offenbach, Germany

11 MediClin Robert Janker Klinik, Bonn, Germany

12 Klinik für Radio-Onkologie, Universitätsklinikum der LMU, Munich, Germany

13 Klinik für Radio-Onkologie, Universitätsklinikum Freiburg, Freiburg, Germany

14 Abteilung Strahlentherapie, Universitätsklinikum Ulm, Ulm, Germany 


\section{Introduction}

External beam radiation (EBRT) is one of the mainstays of the treatment of prostate cancer of all risk groups, to all patients who are in the decision-making process of which treatment to choose. This decision has become more complex recently, since many-equally effective-treatment alternatives are available, including active surveillance or deferred treatment for low-risk (LR) disease. The fact that LR prostate cancer bears a high risk of overtreatment is now unanimously addressed in current relevant guidelines and translates into de-escalated treatment regimens where potential side effects are very carefully weighed against the benefits of a given therapy. In contrast, high-risk (HR) prostate cancer still represents a potentially lethal disease demanding more aggressive treatment.

In this light, ultrahypofractionation qualifies as a viable option in the primary treatment of localized prostate cancer, since it can be tailored to the risk status in terms of fractional and total dose, with or without androgen deprivation therapy. In a situation where LINAC capacities are limited in many countries (or reduced as a side effect of the current COVID-19 pandemic), possibilities to reduce treatment time or fractions without compromising outcome are highly sought after. At the same time, ultrahypofractionation offers a high level of patient convenience due to low overall treatment times without an excess of toxicity. Thus, it is viewed as an attractive alternative to surgery.

In this review we recapitulate the more recent literature (randomized evidence and meta-analyses) on ultrahypofractionation, put it into context with current recommendations, and provide principles which should be followed before introducing ultrahypofractionation into clinical routine.

\section{Terminology}

Extreme or ultrahypofractionation is commonly used synonymously with stereotactic body radiation therapy (SBRT) and stereotactic ablative body radiation (SABR), although the former terms strictly refer to the fraction size, whereas the latter also refer to the platform of beam delivery and radiation technique. We therefore chose to use the term $u l$ trahypofractionation for all forms of delivery of more than $4 \mathrm{~Gy}$ per fraction.

The American Society for Radiation Oncology (ASTRO), American Society of Clinical Oncology (ASCO), and American Urological Association (AUA) hypofractionation guideline [1] defines moderate hypofractionation as 2.4-3.4 Gy/fraction and ultrahypofractionated radiotherapy as doses per treatment of $5.0 \mathrm{~Gy} /$ fraction or higher, thus leaving a "grey zone" between 3.4 and 5 Gy.

The Prostate Cancer Expert Panel of the German Society of Radiation Oncology (DEGRO) and the Working Party
Radiation Oncology of the German Cancer Society (DKGARO) use a definition of 2.2-4Gy/fraction for moderate and beyond $4 \mathrm{~Gy} /$ fraction for ultrahypofractionation [2].

Ultrahypofractionation is usually delivered using highprecision techniques (LINAC based or CyberKnife [Accuray Inc. Sunnyvale, CA, USA]) aided by daily image guidance including adequate motion management strategies allowing for small PTV margins and high dose conformation.

\section{Radiobiology}

While for most cancer types a normofractionation schedule of 1.8-2 Gy per day/five times a week represents the sweet spot in terms of tumor control and toxicity, some tumors exhibit a higher sensitivity to fractional doses and might therefore benefit from hypofractionated schedules. This property is reflected by a low alpha/beta $(\alpha / \beta)$ value and can be quite accurately described with the so-called linear-quadratic model [3]. The $\alpha / \beta$ value is a measure of fractionation sensitivity and is related to the inherent capacity of tumor cells to repair sublethal DNA damage inflicted by ionizing radiation.

Whether hypofractionation is beneficial depends on the $\alpha / \beta$ values of the target in relation to its surrounding normal tissues. For prostate cancer cells, very low $\alpha / \beta$ values of about $1.5 \mathrm{~Gy}$ have been derived from multiple preclinical and clinical studies [4-9]. Late toxicity of the bladder and rectum has been estimated to have an $\alpha / \beta$ value of $5.6 \mathrm{~Gy}$ $[10,11]$ and $3 \mathrm{~Gy}[3,12]$, respectively. Therefore, in theory, hypofractionated radiation schedules should have a beneficial effect on the therapeutic ratio.

More recent data have shown that in addition to fraction dose, overall treatment time seems to play a major role [13], which has been neglected in the aforementioned calculations of the $\alpha / \beta$ ratio ([14] reviewed in [15]). When a time factor is accounted for in the calculation, slightly higher $\alpha / \beta$ values will result, so that many authors nowadays endorse values of approximately $2-2.7 \mathrm{~Gy}$. In a recent meta-analysis, Vogelius and Bentzen calculated $\alpha / \beta$ values based on 13 randomized trials with and without the presence of a time factor of $0.31 \mathrm{~Gy}$ loss per day, yielding $\alpha / \beta$ values of $1.2 \mathrm{~Gy}$ and $2.7 \mathrm{~Gy}$, respectively. Of note, the higher $\alpha / \beta$ derived from hypofractionated dose escalation studies might in part be contributed to the fact that the dose-response relationship starts to max out at approximately EQD2 $80 \mathrm{~Gy}$ - a dose which is superseded by most ultrahypofractionation regimens [16]. It also needs to be emphasized that when comparing EQD2's of different fractionation regimens using the time-corrected $\alpha / \beta$ value, only regimens with the same overall treatment time should be compared. For that reason, we chose to use an $\alpha / \beta$ value of $2 \mathrm{~Gy}$ in the present manuscript, in order to appreciate that ultrahypofractionation regimens have a considerably 
reduced overall treatment time (mostly roughly 2 weeks) compared to normofractionated and moderately hypofractionated regimens.

\section{Cost effectiveness}

In addition to its potential benefit in terms of the therapeutic ratio, ultrahypofractionation may reduce treatment cost for prostate cancer, which, due to its high prevalence, has a major impact on general health care expenses.

It has been shown that ultrahypofractionation is associated with lower overall treatment costs than normofractionated 3D conformal or IMRT [17] as well as moderate hypofractionation [18]. In a recent systemic review comprising 12 studies, Abreha et al. [19] performed a modelbased cost-effectiveness analysis confirming that ultrahypofractionation is the most effective treatment in terms of overall treatment cost, including prostatectomy.

However, most available studies are based on the US Medicare system. For Europe, treatment costs can differ dramatically but there is reason to assume that the relations between different modalities remain similar [20].

\section{Moderate hypofractionation}

For low- and intermediate-risk (IR) prostate cancer, moderate hypofractionation has been shown to be non-inferior to normofractionated treatment in several prospective randomized trials [21-24], and is now strongly recommended in the primary setting by NCCN guidelines [25] and viewed as a viable alternative in current EAU [21] and German S3 guidelines (https://www.leitlinienprogramm-onkologie. de/leitlinien/prostatakarzinom/). The latter two explicitly advise its performance only by experienced teams using high-quality EBRT (IGRT and IMRT) in carefully selected patients, with strong adherence to published phase III protocols.

For HR patients, the benefit of hypofractionated radiotherapy is less clear. Analyses from three large metaanalyses [6-8] comprising more than 20,000 patients have yielded low $\alpha / \beta$ values for all risk groups, which led Fowler et al. to conclude that "the low $\alpha / \beta$ ratio is an intrinsic property of all prostate cancer cells irrespective of their Gleason score or grading" [26]. However, clinical data to support this notion are still lacking. In the three large noninferiority trials [22-24], HR patients were underrepresented. In the superiority design HYPRO trial [25], HR patients were included, but the primary endpoint (improved biochemical control at 5 years) did not reach significance and toxicity was slightly higher in the hypofractionated (and dose-escalated) arm.

\section{Literature review}

\section{Randomized evidence}

\section{The Scandinavian trial (HYPO-RT-PC)}

The Scandinavian non-inferiority design HYPO-RT-PC trial by Widmark et al. [26] randomized men with IR to $\mathrm{HR}$ prostate cancer to receive either $42.7 \mathrm{~Gy}$ in seven fractions, 3 days per week, or conventionally fractionated radiotherapy ( $78 \mathrm{~Gy}$ in 39 fractions, 5 days per week). After a median follow-up of 5 years, failure-free survival was identical (84\%) in both arms. Acute RTOG G2 or worse genitourinary (GU) toxicity was slightly but not significantly increased in the ultrahypofractionated arm at the end of treatment ( $28 \%$ vs. $23 \%, p=0.057)$. A significant rise was only seen at 1-year follow-up (6\% vs. $2 \%, p=0.0037)$, disappearing completely at timepoints thereafter (5-year rate: $5 \%$ in both arms). There was no difference in gastrointestinal (GI) toxicity at any timepoint and no differences in toxicity after 5 years.

Of note, the Widmark trial features some peculiarities and differences compared to the abundant but retrospective trial protocols that have accumulated in the past decade. These differences need to be critically reviewed before routine clinical application:

1. It excluded LR and included intermediate- and high-risk patients: to our knowledge, the Widmark study is the only ultrahypofractionation study in which LR patients were excluded. In addition, a particular subset of HR patients (PSA $<20 \mathrm{ng} / \mathrm{ml}$ and T3a) were included (11\%), which is in stark contrast to the low percentage of HR patients treated within the published retrospective series.

2. It used seven instead of the commonly reported five fractions, which is unique among the ultrahypofractionation trials.

3. No androgen deprivation therapy (ADT) was given: In both arms, ADT was withheld to all patients, which might have had a negative impact on progression-free survival (PFS) as well as overall survival (OS) for (unfavorable) IR and HR patients. For these risk groups, there is no evidence that either hypofractionation or dose escalation (or both) can compensate for the lack of ADT which is known to improve both biochemical control as well as OS [27].

4. The LINAC-based radiation technique did not have to meet highest standards. Neither MR imaging for contouring nor treatment by IMRT were mandatory. In fact, $80 \%$ of patients were treated with conventional 3D planning (commented in [28]).

5. Contouring and margins: Seminal vesicles were not included in the CTV, which is questionable since EORTC 
guidelines recommend including the proximal $1-2 \mathrm{~cm}$ for IR and HR patients, respectively [29]. PTV margins were rather large $(7 \mathrm{~mm})$ even though image guidance was used using either BeamCath ${ }^{\mathrm{TM}}$ (Beampoint $\mathrm{AB}$, Kista, Sweden) (10\%) or gold fiducials $(90 \%)$.

\section{PACE-B}

Early toxicity results of the randomized PACE-B trial have recently been published [30].

In that non-inferiority trial, men with LR or IR prostate cancer (Gleason $7 \mathrm{~b}$ excluded) received either conventional or moderately hypofractionated radiotherapy $(78 \mathrm{~Gy}$ in 39 fractions in 7-8 weeks or $62 \mathrm{~Gy}$ in 20 fractions over 4 weeks, respectively) or SBRT (36.25 Gy in five fractions over 1-2 weeks). ADT was not permitted.

A total of $41 \%$ of patients in the SBRT arm were treated with CyberKnife, $58.3 \%$ with a conventional LINAC using volumetric arc therapy (VMAT). IGRT and intra-fractional motion control were mandatory.

In terms of acute toxicity there was no significant difference between the arms, but a slight trend in favor of the SBRT arm (23\% vs. 27\%). This is in contrast to the Widmark trial, where a trend toward increased acute toxicity was seen in the ultrahypofractionated arm.

\section{Meta-analyses of non-randomized prospective data}

Well over 10,000 patients have been treated within ultrahypofractionated non-randomized prospective protocols, with large variations in fraction size, total dose, and radiation technique. The most relevant studies based on quality and patient cohort size have been summarized and re-analyzed by three large pooled analyses [31-33].

\section{King et al. 2013}

The first pooled analysis by King et al. [31] included 1100 patients from eight institutions who had been treated within prospective phase II trials using CyberKnife with a median follow-up of 36 months. They received a median dose of $36.25 \mathrm{~Gy}$ in $4-5$ fractions. LR (58\%), IR (30\%), and HR (11\%) patients were included. A short course of ADT was given to $14 \%$ of patients. The five-year biochemical relapse-free survival (bRFS) rate was $93 \%$ for all patients and $95 \%, 84 \%$, and $81 \%$ for LR, IR, and HR patients, respectively $(p<0.001)$. Toxicity was not reported.

\section{Kishan et al. 2019}

The second analysis is a cohort study Kishan et al. [32] which analyzed individual patient data from 12 phase II tri- als comprising 2142 men with LR and IR prostate cancer treated with either CyberKnife (7/12 studies) or a conventional LINAC (5/12 studies). 55.3\% of patients had LR disease, $32.3 \%$ had favorable IR disease, and $12.4 \%$ unfavorable IR disease. HR patients were excluded. The followup period was quite long, with a median of 6.9 years.

Seven-year biochemical recurrence-free survival (bRFS) amounted to $95.5 \%$ for LR disease and $89.8 \%$ for IR disease. The crude incidence of acute grade 3 or higher toxic events was $0.60 \%$ for GU and $0.09 \%$ for GI side effects.

\section{Jackson et al. 2019}

The most recent and more extensive review was undertaken by Jackson et al. [33], comprising 6116 patients from 38 prospective studies. There was a large patient overlap with the patient collectives of the former two analyses by King and Kishan et al. A meta-analysis using random effect modeling was performed on a study-level basis. Only studies reporting the same outcome at the same timepoint were pooled, which is an inherent limitation.

At the patient level, 45\% had LR, 47\% had IR, and $8 \%$ HR disease. Median follow-up was 39 months, but 5- and 7-year bRFS rates and toxicities were reported, not complying with the RTOG-ASTRO Phoenix consensus, which recommends the reported date of control be listed as 2 years short of the median follow-up [34].

Combined acute $\geq \mathrm{G} 3$ toxicity was below $1 \%$. Late $\geq \mathrm{G} 3$ GU and GI toxicity was $2.0 \%$ and $1.1 \%$, respectively, and did not change when only studies with a median FU of $\geq 5$ years were analyzed. There was a significant publication bias, which, when corrected for, increased toxicity rates by 1 to $2 \%$. Interestingly, there was an association of dose with late grade $\geq \mathrm{G} 3 \mathrm{GU}$ toxicity but not with $\geq \mathrm{G} 3$ GI toxicity. The authors conclude that ultrahypofractionation could be considered a standard radiotherapeutic strategy for localized prostate cancer-maybe a premature statement given how underrepresented HR patients were in that study.

\section{Treatment of the primary in low-volume metastatic disease setting}

Two recent prospective randomized trials (HORRAD [35] and STAMPEDE [36]) have addressed the role of RT to the prostate in metastatic disease. Ultrahypofractionation is an appealing option in this scenario and has been used optionally in the STAMPEDE trial in which $48 \%$ of patients were treated with $36 \mathrm{~Gy}$ in 6 weekly fractions corresponding to an equivalent dose in $2 \mathrm{~Gy}$ fractions (EQD2 ${ }^{\alpha / \beta}{ }^{2 \mathrm{~Gy}}$ ) of $72 \mathrm{~Gy}$. The STAMPEDE subgroup analysis of low-volume metastatic disease demonstrated a survival advantage in favor of the RT arm (hazard ratio 0.68; 95\% CI 0.52-0.90). The HORRAD trial showed a similar but non-significant 
Table 1 Treatment schedules and corresponding EQD2 for different $\alpha / \beta$ values

\begin{tabular}{|c|c|c|c|c|c|c|c|}
\hline & Dose/fx & No. $f x$ & Total dose & EQD2 $\alpha / \beta 1.5$ & EQD2 $\alpha / \beta 2$ & EQD2 $\alpha / \beta 3$ & EQD2 $\alpha / \beta 10$ \\
\hline HYPO-RT-PC [26] & 6.1 & 7 & 42.7 & 92.72 & 86.47 & 77.71 & 57.29 \\
\hline PACE [30] & 7.25 & 5 & 36.25 & 90.63 & 83.83 & 74.31 & 52.11 \\
\hline $\begin{array}{l}\text { Median fx Jackson } \\
\text { et al. [33] }\end{array}$ & 7.4 & 5 & 37 & 94.09 & 86.95 & 76.96 & 53.65 \\
\hline $\begin{array}{l}\text { STAMPEDE primary } \\
\text { metastatic [36] }\end{array}$ & 6 & 6 & 36 & 77.14 & 72.00 & 64.80 & 48.00 \\
\hline
\end{tabular}

$f x$ fraction, EQD2 equivalent dose in 2 Gy fractions

trend towards an improved OS by RT (hazard ratio 0.68; 95\% CI 0.42-1.10). As a result, the 2019 European Association of Urology and National Comprehensive Cancer Network guidelines now include RT to the prostate as an option in the setting of low-volume metastatic disease [37].

\section{Interpretation}

An accumulating body of retrospective evidence for the safety and efficacy of SBRT for LR and IR prostate cancer has recently been strengthened by the publication of two randomized studies comparing SBRT with a normofractionated schedule, i.e., the Scandinavian trial by Widmark et al. [26] and the first toxicity results of the PACE-B trial [30]. Since the PACE study has not yet reached sufficient followup to report on outcome or late toxicity, the Scandinavian trial is thus far the only randomized trial comparing an ultrahypofractionated to a normofractionated schedule with reported long-term (i.e., 5 years) outcome and toxicity. It is therefore the only level Ib evidence (according to the Oxford Centre for Evidence-Based Medicine, https://www. cebm.net/index.aspx?o=5653) available and has raised the grade of recommendation from $\mathrm{C}$ to $\mathrm{B}$. This could justify the clinical use of ultrahypofractionation outside of clinical trials for low- and intermediate-risk prostate cancer.

HR patients should continue to be treated within clinical trials due to several reasons: First, the body of evidence for LR and IR prostate cancer is overwhelmingly larger than for HR prostate cancer patients constituting well below $8 \%$ of studied patients. In addition, it remains disputable whether Gleason 8-10 prostate cancer cells feature an equally low $\alpha / \beta$ value, although this has been postulated [38]. Third, ultrahypofractionation of the prostate hampers simultaneous coverage of pelvic lymph nodes. Pelvic RT in HR patients is endorsed by many institutions, although its value is still controversially discussed. However, an ultrahypofractionated boost with reduced dose after whole pelvic RT might be an attractive concept $[39,40]$.

ADT has been used inconsistently in the available ultrahypofractionation trials. However, at the present time there is no evidence that high dose can compensate for the lack of ADT in higher-risk prostate cancer. Therefore, ADT should be administered according to the current guidelines, i.e., short-term ADT (4-6 months) for unfavorable IR and long-term ADT (18-36 months) for HR prostate cancer. For favorable IR the omission of ADT seems appropriate in a dose-escalated setting [27].

For ultrahypofractionation, the ideal fractionation regimen has not yet been established. A variety of schedules have been published and can be considered safe (see Table 1 for select examples and corresponding EQD2s for different $\alpha / \beta$ values). With the exception of the Scandinavian trial by Widmark et al., most larger series used doses of 36.25 to $40 \mathrm{~Gy}$ in five fractions administered every other day. In the meta-analysis by Jackson et al., the median fraction size was $7.4 \mathrm{~Gy}$. For unfavorable IR patients, slightly higher total doses may be considered. The seven-fraction schedule by Widmark et al. has been tested in a randomized prospective fashion and can be considered a viable option for IR patients.

For treatment of the primary in the metastatic setting, ultrahypofractionation is an attractive alternative to moderate hypofractionation and has been tested in the STAMPEDE trial. Prolongation of the overall treatment time to 6 weeks is rather unusual for an ultrahypofractionated regimen and may be the reason why in this trial, the alternatively used moderately hypofractionated radiation schedule of $55 \mathrm{~Gy}$ in 20 fractions (daily) showed a slightly better outcome (not significant, HR 0.86 vs. 1.01).

Compared to radiation schedules in the non-metastatic setting, the resulting BEDs of these doses are rather conservative, which owes to the palliative setting where the maxim primum non nocere is to be followed strictly. In general, further studies are needed to establish an appropriate fractionation schedule in the metastasized setting, but if ultrahypofractionation is used, the DEGRO Prostate Cancer Expert Panel favors every-other-day schedules over onceweekly regimens and recommends aiming for a total dose of at least EQD2 $2^{\alpha / \beta 2} 72 \mathrm{~Gy}$.

\section{Conclusion}

Retrospective as well as randomized prospective data with a follow-up of 5 years or more are now available and have 
shown comparable results to recent moderate hypofractionation trials in terms of both biochemical control and toxicity. Although level Ib evidence for ultrahypofractionation is now available, the DEGRO prostate cancer expert panel does not yet recommend ultrahypofractionation for HR patients on a routine basis. However, for centers that are experienced in SBRT and wish to offer ultrahypofractionation to selected LR and IR patients, this seems justified outside of a clinical trial (grade $\mathrm{B}$ recommendation).

In interpretation of the published data, the following principles should be followed when administering ultrahypofractionation in prostate cancer in clinical routine.

1. Ultrahypofractionation is a treatment alternative, amongst moderate hypofractionation and normofractionation, which can be offered outside clinical trials to LR patients who are not suitable for active surveillance and for IR patients including both favorable and unfavorable IR.

2. ADT should be administered according to current guidelines for normo- and moderately hypofractionated regimens, i.e., short-term ADT for unfavorable IR (and longterm ADT for HR patients). For favorable IR, dose-escalated RT alone appears to be an appropriate treatment.

3. Ultrahypofractionation should be administered in a setting of high technical standards. We consider MRbased planning, IMRT/VMAT, and daily IGRT with basic intrafractional control (i.e., imaging after $3 \mathrm{~min}$ of treatment time) as minimum requirements in order to safely achieve PTV margins of approximately $3 \mathrm{~mm}$. In a LINAC-based setting, short treatment times need to be pursued using single-arc VMAT and/or flattening filterfree $(\mathrm{FFF})$ techniques.

4. Dose schedules should strictly adhere to published concepts of larger studies. A maximum fraction size of $8 \mathrm{~Gy}$ and a maximum EQD2 ${ }^{\alpha / \beta 2}$ of $100 \mathrm{~Gy}$ should not be exceeded. In the curative, non-metastatic setting, a minimum EQD2 ${ }^{\alpha / \beta 2}$ of $83.3 \mathrm{~Gy}$ (e.g., $5 \times 7.25 \mathrm{~Gy}$ ) is required. See Table 1 for different fractionation schedules and corresponding EQD2s at different $\alpha / \beta$ values.

5. For treatment of the primary in the metastatic setting, ultrahypofractionation may be used as an alternative to moderate hypofractionation. However, slightly de-escalated schedules with an EQD $2^{\alpha / \beta 2}$ of approximately 72-76 Gy should be used.

6. Patients should be followed up by the treating facility for at least 5 years. Inclusion in a registry study is recommended.

Funding Open access funding provided by Paracelsus Medical University.

Conflict of interest F. Wolf, F. Sedlmayer, D. Aebersold, C. Albrecht, D. Böhmer, M. Flentje, U. Ganswindt, P. Ghadjar, S. Höcht, T. Hölscher, A.-C. Müller, P. Niehoff, M. Pinkawa, N.-S. Schmidt-
Hegemann, C. Zamboglou, D. Zips, and T. Wiegel declare that they have no competing interests.

Open Access This article is licensed under a Creative Commons Attribution 4.0 International License, which permits use, sharing, adaptation, distribution and reproduction in any medium or format, as long as you give appropriate credit to the original author(s) and the source, provide a link to the Creative Commons licence, and indicate if changes were made. The images or other third party material in this article are included in the article's Creative Commons licence, unless indicated otherwise in a credit line to the material. If material is not included in the article's Creative Commons licence and your intended use is not permitted by statutory regulation or exceeds the permitted use, you will need to obtain permission directly from the copyright holder. To view a copy of this licence, visit http://creativecommons.org/licenses/by/4. $0 /$.

\section{References}

1. Morgan SC, Hoffman K, Loblaw DA, Buyyounouski MK, Patton C, Barocas D, Bentzen S, Chang M, Efstathiou J, Greany P, Halvorsen P, Koontz BF, Lawton C, Leyrer CM, Lin D, Ray M, Sandler H (2018) Hypofractionated radiation therapy for localized prostate cancer: executive summary of an ASTRO, ASCO, and AUA evidence-based guideline. Pract Radiat Oncol 8(6):354-360. https://doi.org/10.1016/j.prro.2018.08.002

2. Hocht S, Aebersold DM, Albrecht C, Bohmer D, Flentje M, Ganswindt U, Holscher T, Martin T, Sedlmayer F, Wenz F, Zips D, Wiegel $T$ (2017) Hypofractionated radiotherapy for localized prostate cancer. Strahlenther Onkol 193(1):1-12. https://doi.org/ 10.1007/s00066-016-1041-5

3. Marzi S, Saracino B, Petrongari MG, Arcangeli S, Gomellini S, Arcangeli G, Benassi M, Landoni V (2009) Modeling of alpha/beta for late rectal toxicity from a randomized phase II study: conventional versus hypofractionated scheme for localized prostate cancer. J Exp Clin Cancer Res 28:117. https://doi.org/10.1186/1756-996628-117

4. Brenner DJ, Hall EJ (1999) Fractionation and protraction for radiotherapy of prostate carcinoma. Int J Radiat Oncol Biol Phys 43(5):1095-1101

5. Fowler J, Chappell R, Ritter M (2001) Is alpha/beta for prostate tumors really low? Int J Radiat Oncol Biol Phys 50(4):1021-1031

6. Dasu A, Toma-Dasu I (2012) Prostate alpha/beta revisited-an analysis of clinical results from 14168 patients. Acta Oncol 51(8):963-974

7. Proust-Lima C, Taylor JM, Secher S, Sandler H, Kestin L, Pickles T, Bae K, Allison R, Williams S (2011) Confirmation of a low alpha/beta ratio for prostate cancer treated by external beam radiation therapy alone using a post-treatment repeated-measures model for PSA dynamics. Int J Radiat Oncol Biol Phys 79(1):195-201

8. Miralbell R, Roberts SA, Zubizarreta E, Hendry JH (2012) Dosefractionation sensitivity of prostate cancer deduced from radiotherapy outcomes of 5,969 patients in seven international institutional datasets: alpha/beta = 1.4 (0.9-2.2) Gy. Int J Radiat Oncol Biol Phys 82(1):e17-e24

9. Vogelius IR, Bentzen SM (2013) Meta-analysis of the alpha/beta ratio for prostate cancer in the presence of an overall time factor: bad news, good news, or no news? Int J Radiat Oncol Biol Phys 85(1):89-94

10. Bentzen SM, Lundbeck F, Christensen LL, Overgaard J (1992) Fractionation sensitivity and latency of late radiation injury to the mouse urinary bladder. Radiother Oncol 25(4):301-307

11. Dorr W, Bentzen SM (1999) Late functional response of mouse urinary bladder to fractionated X-irradiation. Int $\mathrm{J}$ Radiat Biol 75(10):1307-1315 
12. Tucker SL, Thames HD, Michalski JM, Bosch WR, Mohan R, Winter K, Cox JD, Purdy JA, Dong L (2011) Estimation of alpha/beta for late rectal toxicity based on RTOG 94-06. Int J Radiat Oncol Biol Phys 81(2):600-605. https://doi.org/10.1016/j.ijrobp.2010.11. 080

13. Thames HD, Kuban D, Levy LB, Horwitz EM, Kupelian P, Martinez A, Michalski J, Pisansky T, Sandler H, Shipley W, Zelefsky M, Zietman A (2010) The role of overall treatment time in the outcome of radiotherapy of prostate cancer: an analysis of biochemical failure in 4839 men treated between 1987 and 1995. Radiother Oncol 96(1):6-12. https://doi.org/10.1016/j.radonc.2010.03.020

14. Vogelius IR, Bentzen SM (2018) Dose response and fractionation sensitivity of prostate cancer after external beam radiation therapy: a meta-analysis of randomized trials. Int J Radiat Oncol Biol Phys 100(4):858-865. https://doi.org/10.1016/j.ijrobp.2017.12.011

15. Baumann M, Holscher T, Denham J (2010) Fractionation in prostate cancer-is it time after all? Radiother Oncol 96(1):1-5. https://doi.org/10.1016/j.radonc.2010.06.001

16. Vogelius IR, Bentzen SM (2020) Diminishing returns from ultrahypofractionated radiation therapy for prostate cancer. Int J Radiat Oncol Biol Phys. https://doi.org/10.1016/j.ijrobp.2020.01.010

17. Sher DJ, Parikh RB, Mays-Jackson S, Punglia RS (2014) Cost-effectiveness analysis of SBRT versus IMRT for low-risk prostate cancer. Am J Clin Oncol 37(3):215-221. https://doi.org/10.1097/ COC.0b013e31827a7d2a

18. Loblaw A (2019) Ultrahypofractionation should be a standard of care option for intermediate-risk prostate cancer. Clin Oncol. https://doi.org/10.1016/j.clon.2019.11.004

19. Abreha SK (2019) Model-based cost-effectiveness analysis of external beam radiation therapy for the treatment of localized prostate cancer: a systematic review. Cost Eff Resour Alloc 17:10. https:// doi.org/10.1186/s12962-019-0178-3

20. Lievens Y, Defourny N, Corral J, Gasparotto C, Grau C, Borras JM (2020) How public health services pay for radiotherapy in Europe: an ESTRO-HERO analysis of reimbursement. Lancet Oncol 21(1):e42-e54. https://doi.org/10.1016/s1470-2045(19)30794-6

21. Mottet N, Bellmunt J, Bolla M, Briers E, Cumberbatch MG, De Santis M, Fossati N, Gross T, Henry AM, Joniau S, Lam TB, Mason MD, Matveev VB, Moldovan PC, van den Bergh RCN, Van den Broeck T, van der Poel HG, van der Kwast TH, Rouviere O, Schoots IG, Wiegel T, Cornford P (2017) EAU-ESTROSIOG guidelines on prostate cancer. Part 1: screening, diagnosis, and local treatment with curative intent. Eur Urol 71(4):618-629. https://doi.org/10.1016/j.eururo.2016.08.003

22. Dearnaley D, Syndikus I, Mossop H, Khoo V, Birtle A, Bloomfield D, Graham J, Kirkbride P, Logue J, Malik Z, Money-Kyrle J, O'Sullivan JM, Panades M, Parker C, Patterson H, Scrase C, Staffurth J, Stockdale A, Tremlett J, Bidmead M, Mayles H, Naismith O, South C, Gao A, Cruickshank C, Hassan S, Pugh J, Griffin C, Hall E, CHHiP Investigators (2016) Conventional versus hypofractionated high-dose intensity-modulated radiotherapy for prostate cancer: 5-year outcomes of the randomised, non-inferiority, phase 3 CHHiP trial. Lancet Oncol 17(8):1047-1060. https:// doi.org/10.1016/S1470-2045(16)30102-4

23. Catton CN, Lukka H, Gu CS, Martin JM, Supiot S, Chung PWM, Bauman GS, Bahary JP, Ahmed S, Cheung P, Tai KH, Wu JS, Parliament MB, Tsakiridis T, Corbett TB, Tang C, Dayes IS, Warde P, Craig TK, Julian JA, Levine MN (2017) Randomized trial of a Hypofractionated radiation regimen for the treatment of localized prostate cancer. J Clin Oncol 35(17):1884-1890. https://doi.org/10. 1200/JCO.2016.71.7397

24. Lee WR, Dignam JJ, Amin MB, Bruner DW, Low D, Swanson GP, Shah AB, D'Souza DP, Michalski JM, Dayes IS, Seaward SA, Hall WA, Nguyen PL, Pisansky TM, Faria SL, Chen Y, Koontz BF, Paulus R, Sandler HM (2016) Randomized phase III Noninferiority study comparing two radiotherapy fractionation schedules in patients with low-risk prostate cancer. J Clin Oncol 34(20):2325-2339. https://doi.org/10.1200/Jco.2016.67.0448

25. Incrocci L, Wortel RC, Alemayehu WG, Aluwini S, Schimmel E, Krol S, van der Toorn PP, Jager H, Heemsbergen W, Heijmen B, Pos F (2016) Hypofractionated versus conventionally fractionated radiotherapy for patients with localised prostate cancer (HYPRO): final efficacy results from a randomised, multicentre, open-label, phase 3 trial. Lancet Oncol 17(8):1061-1069. https://doi.org/10. 1016/S1470-2045(16)30070-5

26. Widmark A, Gunnlaugsson A, Beckman L, Thellenberg-Karlsson C, Hoyer M, Lagerlund M, Kindblom J, Ginman C, Johansson B, Bjornlinger K, Seke M, Agrup M, Fransson P, Tavelin B, Norman D, Zackrisson B, Anderson H, Kjellen E, Franzen L, Nilsson P (2019) Ultra-hypofractionated versus conventionally fractionated radiotherapy for prostate cancer: 5-year outcomes of the HYPO-RT-PC randomised, non-inferiority, phase 3 trial. Lancet 394(10196):385-395. https://doi.org/10.1016/s0140-6736(19) 31131-6

27. Beck M, Bohmer D, Aebersold DM, Albrecht C, Flentje M, Ganswindt U, Hocht S, Holscher T, Muller AC, Niehoff P, Pinkawa M, Sedlmayer F, Zips D, Zschaeck S, Budach V, Wiegel T, Ghadjar P (2020) Role of combined radiation and androgen deprivation therapy in intermediate-risk prostate cancer : Statement from the DEGRO working group on prostate cancer. Strahlenther Onkol 196(2):109-116. https://doi.org/10.1007/s00066-019-01553-3

28. Goldner G (2019) Ultra-hypofractionated versus conventionally fractionated radiotherapy for prostate cancer: HYPO-RT-PC randomized trial. 5-year results: Commentary II. Strahlenther Onkol 195(12):1119-1121. https://doi.org/10.1007/s00066-019-01536-4

29. Salembier C, Villeirs G, De Bari B, Hoskin P, Pieters BR, Van Vulpen M, Khoo V, Henry A, Bossi A, De Meerleer G, Fonteyne V (2018) ESTRO ACROP consensus guideline on CT- and MRIbased target volume delineation for primary radiation therapy of localized prostate cancer. Radiother Oncol 127(1):49-61. https:// doi.org/10.1016/j.radonc.2018.01.014

30. Brand DH, Tree AC, Ostler P, van der Voet H, Loblaw A, Chu W, Ford D, Tolan S, Jain S, Martin A, Staffurth J, Camilleri P, Kancherla K, Frew J, Chan A, Dayes IS, Henderson D, Brown S, Cruickshank C, Burnett S, Duffton A, Griffin C, Hinder V, Morrison K, Naismith O, Hall E, van As N (2019) Intensity-modulated fractionated radiotherapy versus stereotactic body radiotherapy for prostate cancer (PACE-B): acute toxicity findings from an international, randomised, open-label, phase 3 , non-inferiority trial. Lancet Oncol 20(11):1531-1543. https://doi.org/10.1016/s14702045(19)30569-8

31. King CR, Freeman D, Kaplan I, Fuller D, Bolzicco G, Collins S, Meier R, Wang J, Kupelian P, Steinberg M, Katz A (2013) Stereotactic body radiotherapy for localized prostate cancer: pooled analysis from a multi-institutional consortium of prospective phase II trials. Radiother Oncol 109(2):217-221. https://doi.org/10.1016/j. radonc.2013.08.030

32. Kishan AU, Dang A, Katz AJ, Mantz CA, Collins SP, Aghdam N, Chu FI, Kaplan ID, Appelbaum L, Fuller DB, Meier RM, Loblaw DA, Cheung P, Pham HT, Shaverdian N, Jiang N, Yuan Y, Bagshaw H, Prionas N, Buyyounouski MK, Spratt DE, Linson PW, Hong RL, Nickols NG, Steinberg ML, Kupelian PA, King CR (2019) Long-term Outcomes of Stereotactic Body Radiotherapy for Low-Risk and Intermediate-Risk Prostate Cancer. JAMA Netw Open 2(2):e188006. https://doi.org/10.1001/jamanetworkopen. 2018.8006

33. Jackson WC, Silva J, Hartman HE, Dess RT, Kishan AU, Beeler WH, Gharzai LA, Jaworski EM, Mehra R, Hearn JWD, Morgan TM, Salami SS, Cooperberg MR, Mahal BA, Soni PD, Kaffenberger S, Nguyen PL, Desai N, Feng FY, Zumsteg ZS, Spratt DE (2019) Stereotactic body radiation therapy for localized prostate cancer: a systematic review and meta-analysis of over 6,000 pa- 
tients treated on prospective studies. Int J Radiat Oncol Biol Phys 104(4):778-789. https://doi.org/10.1016/j.ijrobp.2019.03.051

34. Roach M 3rd, Hanks G, Thames H Jr., Schellhammer P, Shipley WU, Sokol GH, Sandler H (2006) Defining biochemical failure following radiotherapy with or without hormonal therapy in men with clinically localized prostate cancer: recommendations of the RTOG-ASTRO Phoenix Consensus Conference. Int J Radiat Oncol Biol Phys 65(4):965-974. https://doi.org/10.1016/j.ijrobp.2006.04. 029

35. Boeve LMS, Hulshof M, Vis AN, Zwinderman AH, Twisk JWR, Witjes WPJ, Delaere KPJ, Moorselaar R, Verhagen P, van Andel G (2019) Effect on survival of androgen deprivation therapy alone compared to androgen deprivation therapy combined with concurrent radiation therapy to the prostate in patients with primary Bone metastatic prostate cancer in a prospective Randomised clinical trial: data from the HORRAD trial. Eur Urol 75(3):410-418. https://doi.org/10.1016/j.eururo.2018.09.008

36. Parker CC, James ND, Brawley CD, Clarke NW, Hoyle AP, Ali A, Ritchie AWS, Attard G, Chowdhury S, Cross W, Dearnaley DP, Gillessen S, Gilson C, Jones RJ, Langley RE, Malik ZI, Mason MD, Matheson D, Millman R, Russell JM, Thalmann GN, Amos CL, Alonzi R, Bahl A, Birtle A, Din O, Douis H, Eswar C, Gale J, Gannon MR, Jonnada S, Khaksar S, Lester JF, O'Sullivan JM, Parikh OA, Pedley ID, Pudney DM, Sheehan DJ, Srihari NN, Tran ATH, Parmar MKB, Sydes MR (2018) Radio- therapy to the primary tumour for newly diagnosed, metastatic prostate cancer (STAMPEDE): a randomised controlled phase 3 trial. Lancet 392(10162):2353-2366. https://doi.org/10.1016/ s0140-6736(18)32486-3

37. Nason GJ, Hamilton RJ (2019) Treating the primary in metastatic prostate cancer: where do we stand? Curr Opin Support Palliat Care 13(3):243-248. https://doi.org/10.1097/spc.0000000000000432

38. Fowler JF, Toma-Dasu I, Dasu A (2013) Is the alpha/beta ratio for prostate tumours really low and does it vary with the level of risk at diagnosis? Anticancer Res 33(3):1009-1011

39. Kishan AU, Tyran M, Weng J, Upadhyaya S, Lamb J, Steinberg M, King C, Cao M (2019) Stereotactic body radiotherapy to the prostate and pelvic lymph nodes: A detailed dosimetric analysis of a phase II prospective trial. Br J Radiol 92(1099):20181001. https:// doi.org/10.1259/bjr.20181001

40. Murthy V, Mallick I, Gavarraju A, Sinha S, Krishnatry R, Telkhade T, Moses A, Kannan S, Prakash G, Pal M, Menon S, Popat P, Rangarajan V, Agarwal A, Kulkarni S, Bakshi G (2020) Study protocol of a randomised controlled trial of prostate radiotherapy in high-risk and node-positive disease comparing moderate and extreme hypofractionation (PRIME TRIAL). BMJ Open 10(2):e34623. https://doi.org/10.1136/bmjopen-2019-034623 